\title{
La écfrasis del archivo visual del dolor como estrategia narrativa en la novelística de Pablo Montoya
}

\author{
Carlos Mario Mejía Suárez/ Gustavus Adolphus College
}

\section{Resumen}

La novelística histórica de Pablo Montoya explora el pasado por medio de artefactos visuales donde se registran crisis de sensibilidad en momentos específicos de la historia. En este artículo se explora el desarrollo de la estrategia narrativa de la écfrasis de artefactos de memoria del dolor en sus novelas Lejos de Roma (2008), Los derrotados (2012) y Tríptico de la infamia (2014), prestando atención particularmente a cómo cada obra aborda diferentes maneras de reflexionar sobre la relación entre la literatura, los archivos de dolor y sus significados, ya no como historia registrada y comprendida, sino como exploración de restos latentes dejados por eventos pre-narrativos.

Palabras clave: Novela colombiana contemporánea, Pablo Montoya, memoria cultural, archivo, literatura y arte visual

\begin{abstract}
At the root of Pablo Montoya's novelistic work lies the exploration of the past through visual artefacts that register socio-cultural crisis in specific moments in history. This article analyzes the development of the ekphrasis of visual artefacts of pain as a narrative device in his novels Lejos de Roma (2008), Los derrotados (2012) y Tríptico de la infamia (2014). Particularly, it studies how each work reflects on the relation between literature, archives of pain and their meaning, not as artefacts of a recorded and throughly understood story, but as exploration of latencies left behind by pre-narrative events.
\end{abstract}

Keywords: Contemporary Colombian Novel, Pablo Montoya, Cultural Memory, Archive, literature and visual art.
En entrevista con Norberto Vallejo, el escritor colombiano Pablo Montoya afirma su interés en "indagar en la presencia del arte en esos momentos difíciles, turbulentos que atraviesan nuestras sociedades," (Vallejo 2017) siguiendo perspectivas poco visibilizadas. Desde su primera novela, La sed del ojo (2004), Pablo Montoya ha tematizado en su novelística la interacción entre literatura y artes visuales en la formación de sensibilidades de época. Lo que es más, podemos ver en sus obras una progresión hacia narrativas que hacen écfrasis de fotografía, pintura y grabados como artefactos mnemotécnicos de dolor y placer. Juan Felipe Restrepo afirma que en La sed del ojo "la fotografía erótica se compara con Ovidio. Los dos han ayudado a edificar la sensibilidad, enseñan el cuerpo no como materia y separación, sino como un conjunto de pasiones, sentimientos y pensamientos." (Restrepo 2005, 216) En la novelística de Montoya, el contenido afectivo organiza desde la écfrasis la reactivación de memoria de pasados latentes.

Como afirman Aleida Assmann y Linda Shortt, "Memory has become a central issue in our discussions about transition, as this truth is directly related to the memory of victims, and it is the medium of a new shared narrative of the past that integrates formerly divided perspectives" (Assmann y Shortt 2012, 1). No es casual el posicionamiento central de la comunicación del dolor por medio de archivos visuales en Montoya, quien ha producido su obra en una época en la que Colombia ha visto la emergencia de acuerdos de paz entre el gobierno y grupos armados (paramilitares y guerrilla de las FARC). Sus novelas Lejos de Roma (2008), Los derrotados (2012) y Tríptico de la infamia (2014) reflexionan sobre cómo los archivos visuales reciben tensiones entre lo que se olvida y lo que se recuerda en la construcción del pasado desde el presente. Esta tensión en la narrativa resulta de la sujeción de los archivos visuales a contextos de enunciación que tematizan posiciones diferenciadas de poder dentro de conflictos históricos.

El énfasis en la visibilidad del dolor se plantea en Montoya a partir de la exploración detallada de sus imágenes y prácticas concretas, no en su reducción a una narrativa explicativa. Allí radica el potencial creativo de la interacción entre las artes visuales y la literatura para representar el conflicto violento. La introducción al volumen de estudios culturales Territories of Conflict, refiere la paradoja de que este conflicto sirve como fuerza creativa que no deja de estar dotada de su significado destructivo y que "cultural producers have fully embraced ... as they openly receject conflict while simultaneously using (and needing) it for their creative projects." (Fanta 2017, 1) La obra de Montoya hace 
parte de esta producción cultural que se ancla en el conflicto a la vez que reta su perpetuación oficial por medio de apelaciones extraterritoriales, transhistóricas y de relaciones entre diferentes artes.

Si bien La sed del ojo (2004) se concentra en el replanteamiento del canon artístico a partir de la criminalización de fotografías eróticas en la Francia del siglo XIX, será en su obra posterior donde explorará la visibilidad del dolor haciéndose escritura por medio de extendidas écfrasis integradas en la novela. Desde la publicación de Lejos de Roma (2008) hasta la de Tríptico de la infamia (2014), Montoya ha integrado la reflexión sobre la representación del dolor de los otros de forma cada vez más depurada. En Lejos de Roma, el escritor romano Ovidio narra sus experiencias y decepciones durante su exilio en Tomos, y da un lugar tangencial, pero significativo, a unos dibujos donde un mauritano desplazado por el imperio intenta comunicar su sufrimiento. Por otro lado, Los derrotados (2012) oscila entre la biografía de Francisco José de Caldas y la historia de tres amigos que en algún momento habrían compartido intereses revolucionarios y que convergen en una serie de fotografías que registran masacres ocurridas en Colombia entre 1998 y 2005. Finalmente, en Tríptico de la infamia Montoya organiza la narrativa alrededor de una serie de grabados de la conquista de la Florida (de LeMoyne), una pintura de la masacre de San Bartolomé (de Dubois) y las ilustraciones de la leyenda negra española (DeBry). Este registro visual tripartito representa los abusos del catolicismo en el Nuevo Mundo y en Francia durante la temprana modernidad. Estas tres novelas integran la écfrasis a la visión global del texto narrativo, tematizando las distancias a las que se enfrenta la imagen al reproducir el sufrimiento: distancia entre el pasado y el presente, en la cual radican el olvido y la deformación de los eventos; pero también se trata de distancias con frecuencia controversiales entre lo representado, el productor de la imagen y el receptor de la misma.

\section{Lejos de Roma: imagen y sonido en los márgenes del imperio}

El título de la segunda novela de Montoya nos refiere a la noción más básica de distancia; Lejos de Roma es en últimas una reflexión sobre una distancia espacial. Tras esta definición básica, se oculta una distancia de espacios cargados de significados socio-culturalmente jerarquizados: una distancia entre territorios organizados alrededor de un sentido de colectividad compartido por sus habitantes. El lugar donde ocurre la historia es un margen asociado con el dolor, la muerte y la ansiedad del olvido. Lejos de Roma es la historia de cómo en su exilio Ovidio se desvincula de sus propios recuerdos del imperio oficial y se abre a memorias de sectores olvidados y lugares menospreciados por el imperio. El territorio del imperio se desgaja del sujeto y así, en ese margen, encuentra el horizonte de una posible empatía hacia un mauritano desplazado por la expansión del imperio. Tomos, como territorio del desplazamiento y desclasamiento del sujeto, se complementa con la distancia que separa la materia narrada del contexto de producción, donde un público colombiano del siglo XX reconoce una ficción de tipo histórico que, a la vez, hace referencias veladas y dislocadas a "lo nacional".

Al definir la novela histórica colombiana contemporánea, en Novela histórica en Colombia 1988-2008. Entre la pompa y el fracaso, Pablo Montoya hace explícita la pertenencia de ficciones históricas "extraterritoriales" al canon nacional de dicho género. Montoya incluye su propia Lejos de Roma en este grupo de novelas que quieren "lanzar las preocupaciones del imaginario del escritor a un horizonte histórico extraterritorial" y que "son tan colombianas las novelas que buscan en realidades romanas o turcas ( $E l$ signo del pez de Germán Espinosa y Tamerlán (2003) de Enrique Serrano), como las que narran periplos históricos latinoamericanos o propiamente colombianos ..." (Montoya 2009, x-xi) De esta forma Montoya vincula la voz narrativa con la exploración de líneas que conectan el devenir histórico de Colombia con lo que se suele denominar como "cultura universal". Esta línea de pensamiento sugiere que Montoya encuentra vasos comunicantes entre la materia narrada en su novela, la situación colombiana, y, en particular, la circunstancia del escritor ante problemas postulados por la memoria y el exilio. Montoya genera su obra considerando que la distancia que lo separa del autor implicado y la voz narrativa en primera persona de Lejos de Roma determina no sólo un acercamiento "extraterritorial" a la historia como presunta representación de la "nación", sino que es también una reformulación de lo "universal".

La exploración en la novela de la interacción entre territorio, memoria y escritura sirve para llevar a cabo el cuestionamiento de la petrificación de ideas de lo que es "lo universal". El pasado que la novela navega es, precisamente el de la figura "universal" del autor de Las metamorfosis y de El arte de amar. Sin embargo, la narración hace a un lado los éxitos literarios para concentrarse en su exilio, tras ser acusado y perseguido por el emperador Augusto. El vínculo entre Ovidio y el contexto dentro del cual su imagen se ha hecho universal se encuentran en proceso de desintegración: el autor se reconoce fuera de su territorio, desposeído de la memoria que armaba su identidad y enajenado de la escritura que lo hacía famoso.

Alejado de la performatividad de poder asociada con su pasado como escritor en Roma, Ovidio se ve reducido. La narrativa, sin embargo, comienza a restituirle un tipo de performatividad pública construida a partir de la vulnerabilidad. Si bien se tematiza el carácter desgarrado del personaje, relativiza dicho desgarramiento al contrastarlo con la experiencia de un mauritano desplazado por el imperio y que le muestra una serie de dibujos de las torturas a las que habría sido sometido. Este momento sirve como punto de inflexión en el exilio de Ovidio. Aquí Ovidio logra establecer una conexión con todas las características que 
hasta entonces habrían hecho del espacio y los habitantes de Tomos una otredad. En este momento la fijeza de la memoria petrificada del imperio se hace a un lado para ofrecer el horizonte de posibilidades de una conexión con el mundo que habría resultado de la desposesión, en cuanto pérdida de privilegios.

La pérdida de la posición central de Ovidio en el territorio del imperio hace que el personaje se replantee el valor de lo perdido. En Tomos, Ovidio descubre o acepta las bases de explotación sobre las que avanza el imperio. La obra en general es una exploración ficcional de esa voz del exiliado; voz hecha de imágenes, experiencias e ideas interiorizadas en las que Montoya teje exploraciones transhistóricas y extraterritoriales capaces de extenderse al contexto colombiano en el siglo XX. Es así que al ver a una masa de personas que se desplazan en las inmediaciones, Ovidio reflexiona: "Conozco lo que el Senado llama paz y civilización, y sé que en otros, en éstos que pasan a mi lado por ejemplo, nuestra paz no es más que espanto y fuga" (Montoya 2008, 68-69). El desplazamiento de su subjetividad reformula los conceptos de paz y civilización, que invocan y cuestionan -fuera del texto, para un lector colombiano y latinoamericano- los manidos significados que estas palabras tienen para la intelligentsia decimonónica con su dicotomía "civilización vs. barbarie", o la muy contemporánea manipulación de conceptos de paz y seguridad democrática en Colombia. Más adelante, precisamente, Ovidio se concentra en esa "paz" diciendo que "se adquirió después de miles de muertos, porque Roma es todo eso. Huesos desparramados trazando las fronteras del imperio" (Montoya 2008, 102); cuestionando así no sólo ideales abstractos, sino la violencia corporal de la frontera del imperio. El acto de marcar la frontera del imperio estaría directamente vinculado con el dolor y el exterminio de vidas marginadas.

El principio de este replanteamiento se encuentra cuando el mauritano le muestra imágenes de las torturas a las que fue sometido. Sin poder entender sus palabras ni el posible ordenamiento lógico que el hombre da a los eventos, Ovidio se conecta con la memoria de ese "otro" y con los horrores que la paz del imperio oculta. El solo hecho de ver los dibujos parece una transgresión y Ovidio sabe que "debería cerrar los ojos, y que podría hacer un reclamo por esta presión", pero este deseo de ignorar el dolor del otro se contrarresta con "un sentimiento similar a la piedad me mueve hacia el hombre" (Montoya 2008, 40). El mauritano parece llevar consigo un soporte visual de su memoria, que actualiza el dolor en el momento de interacción con Ovidio. En este momento, esa memoria ajena lo conduce al cuestionamiento de su propia memoria. El episodio termina, de manera muy significativa, no con una reflexión completamente formada de la empatía con el mauritano, sino precisamente con el reconocimiento de una distancia radical que lo separa, pero que impacta la forma en que el personaje entiende afectivamente su circunstancia; afirma que en ese momento "lo único que suena en el mundo, mientras pasan esas imágenes por mis ojos, es la letanía sollozante del hombre que no cesa" (Montoya 2008, 40). En este momento la memoria del mauritano queda al margen de lo verbal, pero se sugiere por medio de artefactos visuales que forman un archivo personal. El sonido de la voz del mauritano queda reducido a sugerencia potencial de la memoria, pero Ovidio ni siquiera intenta capturar dicho sonido. Tenemos una voz y una memoria perdida que no se recupera y que obliga a Ovidio a reconocer los límites de su comprensión.

El momento de interacción con la imagen cuestiona la ideología del archivo de artefactos que crearía una memoria colectiva con tendencia a la fosilización y la homogeneidad del significado. Como afirma Susan Sontag, "what is called collective memory is not a remembering but a stipulating: that this is important, and this is the story about how it happened, with pictures that lock the story in our minds. Ideologies create substantiating archives of images, representative images, which encapsulate common ideas of significance and trigger predictable thoughts, feelings" (Sontag 2003, 86). Es precisamente el estatuto inestable de la conexión entre Ovidio y el mauritano lo que produce la formación de un horizonte de posibilidades afectivas que trascienden el refuerzo del imperio o de pensar en el mauritano como víctima. Se trata de un dolor que escapa al "encapsulamiento" de una idea común. Incluso el dolor que se reproduce en la narrativa está concentrado en "el otro" y el narrador evita decir algo más de ese dolor; algo que no sea la materialidad de la voz... e, incluso, evita proponer una forma de "colectividad" entre ellos dos.

\section{Los derrotados (2012): botánicos, fotógrafos y rebeldes en la creación novelística de un archivo de lo nacional}

El llamado período de post-conflicto o post-acuerdo ha impactado nuestro acercamiento a la memoria del pasado al cuestionar la unificación del pasado de violencia en una sola narrativa englobante. Como afirma Eduardo Pizarro Leongómez en Contribución al entendimiento del conflicto armado en Colombia, el acercamiento a la memoria histórica del conflicto está "lejos . . . de una imposible e indeseable 'historia oficial' o de una igualmente imposible e indeseable verdad única" y propone antes bien una "invitación al diálogo pluralista y democrático" (Pizarro 2015, 19). Este acercamiento contemporáneo a la historia y la memoria viva del conflicto sigue una oscilación entre violencias históricas que ya se entienden como continuidad, ya como rupturas.

La memoria que se invoca en archivos visuales como los que hemos observado hasta ahora en la obra de Montoya está sujeta a regímenes de simbolización que no se pueden reducir a una verdad oficial del pasado. Estos artefactos visuales son parte de órdenes de simbolización que, según Astrid Erll, "include, among other aspects, value hierarchies and an understanding of temporal processes. Within this complex, symbolically mediated 'world of action', our 
experiences are characterized by their "pre-narrative quality" (Erll 2011, 153). El texto literario se convierte en campo de contienda de cómo el exceso extra-literario y pre-narrativo del evento se imagina y se simboliza dentro de cánones de género discursivo. Más específicamente, el texto literario puede convertirse en mecanismo creador y perpetuador de memorias y de regímenes de simbolización de la experiencia; o puede ser texto que reflexiona sobre la memoria misma para cuestionar y replantear dichos regímenes. En Los derrotados (2012) Montoya utiliza el texto como reflexión sobre la interacción entre memoria e historia a partir de la écfrasis. Los personajes de esta obra se pueden leer como diferentes intentos de abordar el mundo pre-narrativo de la acción, y la écfrasis es el procedimiento estilístico central para reflexionar acerca de los procesos temporales subyacentes a la creación -entre otras cosas fallida- de una memoria cultural colectiva.

En Colombia falla la ideología que habría estabilizado lo nacional por medio de archivos sustantivos que ratifican los hechos, las ideas y los sentimientos del público receptor. $\mathrm{O}$ al menos esto es lo que sugiere Los derrotados cuando no sólo se crea una visión histórica ficticia de Francisco José de Caldas, prócer de la patria, sino que además constituye una voz narrativa que juega con archivos botánicos en el contexto de las guerras de independencia y archivos fotográficos de masacres en el contexto del conflicto colombiano contemporáneo. A diferencia de Ovidio que en Lejos de Roma se queda con el dibujo y el dolor pronunciado en una lengua ajena, los personajes de Los derrotados hacen parte del cúmulo de perdedores que quedan excluidos del sistema socio-político colombiano y, por tanto, indefensos a la imposición de la narrativa ideológica que enmarca y da sentido a su derrota. De allí que la novela presenta la écfrasis del diario del botánico y del proyecto del fotógrafo Andrés Ramírez, como completamente sujeta a un orden cronológico externo al que ni siquiera la reflexión crítica de los personajes puede escapar. Como productores de fotografías, ficciones y rebeliones, los personajes de Los derrotados reúnen archivos visuales (ya reales o ya imaginados dentro de la trama) tematizando así cómo se procesan la experiencia y el testimonio en forma narrativa.

La novela sigue la historia del prócer de la independencia colombiana, Francisco José de Caldas, concentrándose en su trabajo como científico y explorador asociado con la expedición botánica de Nueva Granada coordinada por José Celestino Mutis. Su historia desemboca en los enfrentamientos del período conocido como "patria boba" y en la pacificación española de Pablo Morillo, quien ejecuta a Caldas. Este eje narrativo abre el relato y es una ficción producida por Pedro, personaje que contacta a un editor para publicar la biografía de Caldas. Pedro recuerda a sus amigos de colegio, Andrés y Santiago. El eje narrativo que se concentra en Andrés explora la relación problemática entre el arte fotográfico y los compromisos revolucionarios que algunos de los compañeros de colegio habrían comenzado a forjar desde su temprana adolescencia. Andrés se convierte en fotoreportero para un periódico, lo cual lo lleva a registrar masacres ocurridas entre 1998 y 2005. Finalmente, el eje narrativo de Santiago se concentra en las operaciones de un grupo guerrillero al que él se habría unido desde la adolescencia (EPL), su eventual desarme y las consecuencias de dicho desarme para el grupo.

Aquí nos concentramos en dos episodios en los que la narración tematiza la relación entre el archivo visual, su transformación en registro escrito y su consecuente estatus como estipulación de lo que importa. El primer momento ocurre en el capítulo 10, donde el lector encuentra el diario de Francisco José de Caldas entre el 22 de julio de 1802 y el 5 de junio de 1805 . Se trata de la ficción histórica que Pedro produce y que eventualmente es rechazada $\mathrm{y}$, por tanto, no se ve publicada. En este diario se incluyen las reflexiones científicas, personales y filosóficas del prócer de la nación colombiana, a manera de contexto al proceso de acumulación llevado a cabo por la Expedición Botánico de José Celestino Mutis, y de la cual Caldas habría hecho parte. Sabemos que la tarea realizada por Mutis compendió fauna, flora y topografía neogranadinas, pero que a la vez quedó sujeta al contexto violento de la emancipación americana y la reconquista española, cuando fueron confiscados en 1816 y "sent to Spain. They remained there, undiscovered, for some 150 years. Approximately 5,300 drawings were recorded on folio sheets and represent a foundational mapping of New Granada" (LaRosa y Mejía 2012, 158). Se entiende así el carácter marginal y vulnerable de este archivo "fundacional" del entendimiento del territorio colombiano. La narrativa de Montoya exacerba esta vulnerabilidad cuando se afirma que el trabajo de Caldas habría desaparecido debido al descuido de Mutis. La creación del diario ficticio no gratuitamente, se esfuerza por establecer una conexión entre el material investigado (las plantas de la Nueva Granada) con las ansiedades del intelectual que participa en la creación del archivo visual, particularmente las que tienen que ver con el carácter transitorio de sus observaciones, la sensación de discontinuidad de las mismas y el desarrollo del conocimiento botánico y científico de su muy provincial tierra.

La forma en que el personaje de Pedro ficcionaliza el acto de recolección de Caldas sugiere la formación de una clave de lectura para el laberinto del territorio colombiano, como nación en su momento de origen. Pedro crea diferentes capas para dicha clave de lectura: por un lado se nos refiere el cuidado y preciso proceso de recolección y acumulación de muestras; por otro lado tenemos el diario reflexivo donde Caldas encuentra "el camino para salir del laberinto en que me han cercado las plantas es recoger, describir, diseñar aquello que mi precariedad pueda observar" (Montoya 2012, 123). Es una clave que mira al territorio reconociendo que lo visto y recolectado ya se ha quedado en el pasado: que las muestras y el diario son memoria y clave de lectura de plantas sacrificadas en beneficio del archivo. Llama la atención la insistencia de Caldas en su propia precariedad y 
en las limitaciones de su mirada. En este breve archivo de la vida vegetal neogranadina, el Caldas de Pedro se refiere con frecuencia a la conexión entre las plantas listadas y diferentes formas de memorializar: desde el guayacán como continuidad del ser después de la muerte, hasta las clemátides, que según los chamanes del Mira "al beberla todos los días, en el hombre se prenden todo tipo de evocaciones, y se presentan las asociaciones entre lo que ya pasó, lo que sucede y lo vendrá" (Montoya 2012, 130). Más que la conformación de un archivo instrumental para la explotación de los recursos de la Nueva Granada, Pedro plantea aquí que para Caldas lo fundamental de esta exploración es la posibilidad de conectarse significativamente con el pasado. Es diciente que en la trama de Los derrotados el relato de Pedro jamás es publicado debido a que el potencial editor piensa que no tendrá una audiencia. Así como Caldas termina su diario sintiendo la precariedad de su tarea y la facilidad con que su clave memoriosa puede perderse, particularmente en los remolinos de la guerra, el manuscrito de Pedro parece condenado al olvido. Se trata de la derrotada imaginación literaria de un archivo botánico-filosófico igualmente suprimido del recuerdo de la nación.

El segundo momento de la novela donde se tematiza esta relación entre un archivo visual y su transformación en un registro escrito es el capítulo 17, donde Pedro visita a su amigo, el fotógrafo Andrés Ramírez. Éste le muestra un proyecto donde recopila las fotografías que ha tomado en su trabajo como reportero para un periódico local en un período de tiempo que cubre desde 1997 hasta febrero de 2005. En la trama de la novela, este capítulo sirve para que Pedro descubra el desafortunado destino de su amada, pero este momento de anagnórisis o reconocimiento de una pérdida sentimental se complementa con una realización más profunda vinculada a la acumulación de imágenes de dolor ajeno en la violencia nacional. Aquí la ficción se entrecruza con la realidad histórica; Montoya crea el archivo fotográfico de Ramírez basándose en el trabajo del fotógrafo Jesús Abad Colorado, convirtiéndolo en versión ficcionalizada. De esta manera la composición de Los derrotados refleja el proceso escritural de Pedro con respecto al diario de Caldas. Esta superposición de niveles ficcionales en la narrativa sugiere nuevamente que la dinámica entre la reproducción directa de lo que ve el ojo, su representante en mecanismos tecnológicos (como la cámara fotográfica o el uso de cierto tipo de papel para preservar muestras, etc) y su écfrasis escritural constituye la cifra de una memoria donde se guarda el mapa para entender el laberinto del territorio colombiano, ya sea en lo que respecta a los misterios de sus selvas o en lo que respecta a las horribles contradicciones de sus violencias.

El capítulo 17 sigue cronológicamente diferentes masacres emblemáticas y a la vez ofrece una resemantización de las imágenes del fotógrafo, rescatándolas de su uso mediático. Previamente en la novela se afirma que en el periódico El Colombiano usaban sus fotos para ilustrar reportes falsos y que no le permitían a Ramírez participar en la elaboración del texto:

Lo que no le gustaba al periódico era que se supiera de qué modo se relacionaban los paramilitares, el ejército y los hacendados para asesinar no sólo a guerrilleros, sino a los campesinos que se encontraban en las regiones de esa lucha. Una lucha que, y Ramírez lo decía, se hacía por el dominio de los corredores de la droga. (Montoya 2012, 153)

Hay en este momento, nuevamente el reconocimiento de una vulnerabilidad de la imagen, ya no tanto con respecto a la destrucción de la materialidad del registro visual, sino con respecto a la forma en que depende del marco que se le provee. Si pensamos en la afectividad como horizonte de potencialidades resignificantes de cuerpos en contacto con el mundo circundante, el archivo fotográfico de Andrés Ramírez/Jesús Abad Colorado ilustra cuestionamientos éticos acerca de la reducción de los registros del dolor del cuerpo. Su fotografía le devuelve a dichos registros de dolor el potencial de afectar y ser afectado por otros, extrayéndolos de su relación con textos que manipulan su relación con la realidad para fijarla de manera acrítica y engañosa.

La caracterización de Ramírez se produce en este capítulo por medio de una referencia a reflexiones de Susan Sontag sobre la ética de la representación visual y fotográfica del dolor de los otros. De esta manera Ramírez, como profesional, parece acercarse de forma reflexiva al posicionamiento de la cámara en los conflictos armados. No sería ajena para él la idea de que "war-making and picturetaking are congruent activities: 'It is the same intelligence, whose weapons of annihilation can locate the enemy to the exact second and meter,' wrote Jünger, 'that labors to preserve the great historical event in fine detail"” (Sontag 2003, 66-67). La tecnología de la cámara fotográfica en este capítulo se convierte en representante de la distancia entre el observador y las víctimas; más que esto, es la marca de que esa misma distancia es la que permite las atrocidades de las masacres registradas. La novela reproduce esta distancia, y desde ella se permite la creación del fotógrafo ficticio pero poblándola con imágenes extraídas de la realidad pre-literaria, que antecede al proceso creativo de Montoya. Esta distancia se revela a sí misma, creando un espacio de ficción entre la verosimilitud de la historia y las imágenes que anteceden a dicho discurso.

Los derrotados se concentra en la confluencia de perspectivas en la producción de artefactos que pueden o no pasar a formar parte del acervo de la memoria cultural colombiana. Se trata de objetos acumulados en diferentes manifestaciones del archivo, ya sea a través de dibujos realizados en el contexto de una expedición botánica, testimonios, cartas, obras de ficción histórica o fotografías. Se puede decir que la novela se arma a partir de la confluencia de actores del conflicto, víctimas e instancias que observan 
los eventos de forma mediada. Cada trama de la narrativa puede corresponder a uno de estos puntos en confluencia. La historia de Santiago Hernández, como miembro activo y eventualmente desmovilizado de un grupo guerrillero, encarna el pathos de un actor del conflicto que es torturado por el ejército. Por otro lado, al seguir las búsquedas periodísticas de Andrés Ramírez nos encontramos con la historia de Alba y su hijo desaparecido. El observador que registra visualmente la violencia está encarnado en el personaje de Andrés Ramírez, cuya cámara sirve como punto de entrada a la historia de las víctimas. Finalmente, Pedro constituye a otro tipo de observador que sirve como guía para hacer de la imagen discurso escrito. En otras palabras, esta última instancia constituye el punto del cual emana la écfrasis de lo visual que en últimas hace confluir a las demás instancias. No es casual que en el capítulo 17 coexistan actores, víctimas y observadores. Lo que es más, allí la imagen que se presenta como emblemática del conflicto armado y de la obra del fotógrafo, está marcada por ausencias. Véamosla en detalle.

Al registrar la masacre de Juradó, Andrés da con la imagen de la que se va a valer para la cubierta de su proyecto fotográfico y que en su opinión es "la imagen que nombra por antonomasia al país" (Montoya 2012, 226). Allí, el fotógrafo se concentra en un objeto que se halla tirado en el suelo y que es

un espejo roto en pedazos. Es una bagatela sin mayor valor económico. Uno de esos espejuelos que se venden a mil pesos en los mercados de abalorios de aldeas habitadas por indígenas y negros pobres. Ramírez ha caminado una vez más por uno de esos sectores devastados y ha mirado a sus pies. Porque el espejo está tirado en el suelo. Varias balas, que parecen cuscas de cigarrillos aceradas, lo rodean. La tierra de Juradó, como el espejo, está agrietada. En los espejos, como en la tierra, no hay ningún reflejo. (Montoya 2012, 226)

Las fotografías de Andrés nunca se regodean en el registro morboso de cuerpos y sangre, sino que buscan la humanidad de la víctima y su dolor. Pero esta imagen resalta en su obra porque se concentra en los rastros, en los pequeños objetos que funcionan para referirse a quiénes podrían ser las víctimas, su posición social, su etnia... a quiénes podrían ser los perpetradores de cuyas armas salieron esas balas consumidas y exhaustas en el suelo alrededor del espejo... y lo que es más, el espejo no guarda en su reflejo registro de destrucción ni víctimas ni perpetradores, ni de observadores. El espejo sugiere la presencia de un observador que podría ser el fotógrafo, pero el ángulo lo oculta; o que podría ser el observador distante de la fotografía, resguardado de ser registrado en ese espejo gracias a la distancia tecnológicamente creada y que lo separa del evento pre-narrativo. Esta imagen sugiere los vectores divergentes de los diferentes implicados en el conflicto. Sólo los une este pequeño recordatorio de los rastros que deja la violencia en un momento y lugar del pasado, ahora perdidos.

Dos líneas distinguen la inclusión de estos capítulos. Por un lado, nos encontramos frente a la descripción de un artefacto visual de memoria. Dichos artefactos están sujetos a una cadena cronológica ineludible presentada como registro de momentos singulares que van acumulando la posibilidad de afectar a quien descubra su existencia al margen de discursos hegemonizantes. En este sentido, la novela tematiza el procedimiento de creación del archivo que precariamente se preserva para la historia. Por otro lado, el lector se encuentra con la voz de los productores y reproductores de dichos artefactos, reflexionando sobre la naturaleza de los mismos, sus aspiraciones y limitaciones. De esta manera, el objeto archivado adquiere una dimensión personal ya que se vincula a pensamientos, experiencias, conocimientos, dudas, deseos y aspiraciones de tipo completamente individual, pero no por ello menos comunicables a otros. Finalmente, la eventual pérdida de dichos artefactos o su poca resonancia -o manipulación- en el nivel colectivo, invita a la revaluación de formas culturalmente estabilizadoras de la experiencia pre-narrativa.

\section{Tríptico de la infamia (2014): Las infamias de la memoria y la memoria de las infamias.}

La novela Tríptico de la infamia está profundamente conectada con la dinámica entre "experiencias prenarrativas", arte visual y la revaluación del archivo de memoria cultural. En cierta forma, esta novela asemeja inquietudes de Ramírez en el capítulo 17 de Los derrotados acerca del poder de las imágenes en la representación del sufrimiento. Esta reflexión de Ramírez sigue ideas de Sontag para revelar lo oculto y "para molestar la conciencia del vidente. Quienes lloran en [sus fotografías] pertenecen a los estratos abandonados de la población ... Es el pueblo quien llora en las fotografías..." (228) La incomodidad de la relación entre el espectador y la imagen fotográfica es precisamente el centro del trabajo Andrés Ramírez y en la trama entra en tensión con la reproducción masiva de la imagen en la prensa. Ramírez sabe que la imagen es obligada a supeditarse al texto manipulado del periódico y, como alternativa, la creación de un libro que reúne su trabajo procura rebelarse contra el texto periodístico desde el cual la profesión de Ramírez se ejecuta y del cual depende. De forma similar, Montoya afirma en la ya citada entrevista con Norberto Vallejo que su Tríptico de la infamia se ocupa de explorar una perspectiva oculta en el conocimiento histórico de la temprana modernidad y de la conquista de América: la de los artistas e ilustradores.

Tríptico de la infamia se organiza en torno a esta dinámica entre el dolor representado, la técnica visual y la difícil relación entre la imagen y el texto final que la enmarca; pero ubicándose en un entramado que extiende los hilos del presente no sólo al pasado nacional, sino a líneas extraterritoriales al centrarse en episodios de violencia 
infame que tuvieron lugar durante la temprana modernidad europea y el principio de las empresas coloniales europeas en América. A diferencia de Lejos de Roma, Tríptico... reproduce el mecanismo que Roberto Burgos Cantor utiliza en La ceiba de la memoria (2007), al traer al frente de la visión del lector el proceso de investigación. La narrativa, como su título lo sugiere, es un tríptico en tres "paneles". En el primer panel encontramos al ilustrador Le Moyne, quien se une a la empresa de conquista de los hugonotes en la Florida, bajo el mando del capitán Laudonnière. A partir de esta experiencia LeMoyne crea acuarelas de su encuentro con los indígenas de la Florida. Tras un ataque de tropas españolas al mando de Avilés, LeMoyne se ve obligado a volver a Europa. El segundo panel sigue al pintor Dubois, quien encuentra el amor en la mujer que LeMoyne habría dejado atrás para viajar a América, pero quien desaparece durante la masacre de San Bartolomé. Dubois sobrevive la masacre $y$, tras un periodo en el que el trauma lo silencia, finalmente deja registro de la masacre en el cuadro "Masacre de San Bartolomé". La tercera parte de la novela se concentra en el personaje de DeBry, editor y grabador que se vale de las imágenes de Le Moyne, Dubois y John White para producir textos que movilizan la leyenda negra de la conquista española en América. En esta tercera parte, De Bry funciona como doble funcional del narrador/autor, quien a su vez se manifiesta ficcionalmente al incluir momentos de su propio proceso de investigación en las ciudades europeas donde busca los registros de sus personajes, llamando la atención brevemente sobre la continuidad entre la violencia del pasado manifestada universalmente alrededor de la investigación histórica y las violencias contemporáneas y colombianas que dejan huella en la memoria del personaje investigador. Nótese que este tercer panel se ocupa precisamente de la interacción entre la imagen y el texto, creando paralelos entre la figura del editor/grabador/impresor y la figura del escritor. DeBry, en principio simplemente editor, se manifiesta casi como un escritor que reúne piezas de una colcha multicolor; en tanto que el personaje del investigador hace que el texto resultante de la investigación se asemeje a lo que realiza un editor.

La organización de las narrativas que componen la novela continuamente reflexionan acerca del proceso de construcción de la memoria colectiva y cómo se acerca a lo desconocido y lo olvidado como espacios de potencialidad. La novela inicia con el momento en que LeMoyne se une al taller de Phillip Tocsin y allí él se instruye en la elaboración de mapas y en cómo llenar las geografías desconocidas con representaciones simbólicas. En la segunda parte, Dubois termina su terrible representación de la masacre de San Bartolomé concentrándose en los afectos perdidos durante la misma, su amada Ysabeau y su gato. Al final de la obra DeBry termina de imprimir su libro ilustrado sobre los Grandes viajes y enciende velas en memoria de Bartolomé de las Casas con el propósito de "también de olvidar un poco. Porque es deber hacerlo antes de llegar al fin. Dos velas blancas se prendieron entonces." (Montoya 2015, 303)
Tríptico de la infamia se ocupa de explorar con écfrasis los detalles de simbolización visual tras los cuales se encuentra la duda, la pérdida, lo desconocido y el olvido.

Entre la experiencia, la imagen visual y la écfrasis que la transplanta e intenta fijar, se desliza una dimensión supra-individual del dolor y de su uso para conformar una memoria colectiva. La memoria entre estos tres momentos definitivos se forma como un juego de interacciones entre tres elementos: 1. formas culturales de simbolización, 2. recuerdo afectivo siempre presente desde una subjetividad hecha texto y 3. el imperativo de olvidar algo a la vez que se conmemora el pasado en la voz que organiza la narrativa global.

De la misma manera que el archivo fotográfico de Andrés Ramírez, cada uno de estos capítulos incorpora detalladas descripciones de obras gráficas que se encuentran archivadas en diversas colecciones y que han aparecido publicadas y hasta se pueden encontrar en línea. Aquí, sin embargo, se encuentran rastros de archivos eliminados, artefactos y escrituras que la violencia sepultó y que ahora son más bien contenido ficcionalizado. Al narrar la historia de LeMoyne, el narrador contrapone a la empresa colonizadora el desarrollo personal del pintor e ilustrador: por un lado encontramos la secuencia de acuarelas descritas de manera similar al archivo fotográfico de Ramírez, pero por otro se sugiere desde el trasfondo de la historia la fascinación de Le Moyne por la práctica de los tatuajes entre los indígenas de Saturiona. Esta tensión se tematiza cuando los tres personajes responsables del registro de los eventos, Le Moyne, el poeta LaCaille y el pastor L'Habit, debaten ideas sobre la humanidad de los indígenas y se afirma que

la pintura que se hacían en el cuerpo, los indígenas encontraban el camino más eficaz para desprenderse del tiempo o acaso para llegar a uno de sus secretos más profundos. Era como un pasatiempo en el que participaban todos los integrantes de la tribu con el fin de justificarse y a la vez negarse ante la existencia, ante ellos mismos $\mathrm{y}$ ante sus antepasados. Frente a un mundo poblado de dioses y a la vez de nada... Y aquí era cuando Le Moyne buscaba a sus interlocutores para contarles el mito creador de los timucuas que había tratado de entender. Pero se daba cuenta, descorazonado, de que La Caille y L'Habit retomaban sus ocupaciones. El sargento, la escritura de un extenso poema llamado "La floridiana"; y el pastor, su lectura de los Evangelios." (Montoya 2015, 57)

En este momento Montoya crea la imagen de la producción del archivo de la violencia de la conquista alrededor de estos tres hombres y el fracaso de unificar dicho archivo. Lo que es más, Le Moyne reconoce la pérdida de la memoria ritual practicada alrededor de los tatuajes, con 
desilusión de ver al poeta y al pastor encerrándose en las convenciones propias de prácticas escriturales europeas.

El segundo fresco narrativo de Tríptico parece aglutinar la caracterización de Dubois alrededor del momento en que, tras sobrevivir la masacre de San Bartolomé, es abordado por otros para representar lo ocurrido y entonces piensa que "Lo que habría que preguntarse ahora es qué hacer con esos fantasmas insepultos. ¿Cómo introducirlos en la pintura que debo - ejecutar? ¿De qué manera lograr que con unos cuantos rasgos se exprese la dimensión de un mundo despiadado?" (Montoya 2015, 183-184). La tensión entre el olvido y la memoria se manifiesta aquí alrededor de la manera de incluir aquello que está ausente y de lo cual queda una memoria individual poco confiable, que es lo que el propio Dubois piensa acerca de su memoria. Es en la interacción con otros y sus procesos de simbolización y de organización social, que Dubois logra reactivar, no necesariamente los hechos del pasado como realidad, sino su representación en un lenguaje que, por medio del registro visual, se une al acervo social y cultural de las víctimas.

Aún antes de la masacre, ya la historia de Dubois incluye la descripción de un momento de memorialización de víctimas. Después de que las masacres de hugonotes franceses ocurren en la Nueva Francia de la Florida, y se tiene noticia de desaparecidos que no regresaron, Dubois refiere la movilización de familiares en las calles y dice que

Allí aparecían los nombres y se llevaba un objeto o una prenda de las personas asesinadas y secuestradas por los españoles. En dónde están, los queremos de regreso, gritaban con fuerza esos corrillos en los que yo solía encontrarme. Una noche se hizo una procesión. Todos portábamos una vela prendida y solicitábamos en silencio que nuestros seres queridos fuesen enterrados cristianamente. Que se levantara, en torno a su desaparición, un túmulo funerario que hiciese memoria de ellos. Pero esas multitudes eran dispersadas con violencia y se nos obligaba a volver a nuestros domicilios con la indignación todavía más exacerbada y la esperanza completamente envenenada por la impotencia. (Montoya 2015, 149)

Este momento que prefigura la eventual intervención de Dubois en el archivo de la violencia religiosa contra los hugonotes a través de la elaboración de su tabla sobre la masacre de San Bartolomé, invoca curiosamente imágenes contemporáneas de manifestaciones contra la violencia en las dictaduras del cono sur latinoamericano, o en contra de secuestros, masacres y desapariciones en el caso colombiano. Este momento en realidad funciona para prefigurar lo que se convertirá en el centro del tercer segmento narrativo, ya que en éste observamos la forma en que el registro del pasado, ya sea simbólico, artístico o testimonial, hace ecos de sí en situaciones disímiles; crea una especie de hipertexto, que
Montoya quiere hacer visible para el lector. Después de narrar los años de formación de DeBry y su búsqueda de nuevos horizontes en Amberes, el narrador se visibiliza a sí mismo expresando que

Lo que me interesa resaltar de esta estadía, en todo caso, es el encuentro de Théodore de Bry con un libro. Mientras recorro las viejas calles de Amberes, cubiertas por las hojas empantanadas del otoño, y veo en las librerías de anticuario reproducciones de los mapas de Ortelius, imagino el momento en que Théodore de Bry lo halló ... El ejemplar que leyó De Bry fue la traducción de Brevísima relación de la destrucción de las Indias, de Bartolomé de las Casas ... (Montoya 2015, 210)

Nuestro narrador aquí tematiza la forma en que las diferentes líneas narrativas de la novela, cada una independiente, se entrecruza, por medio de una figura que le da contenido afectivo al momento del contacto por medio de la imaginación. La novela delínea claras relaciones entre la pervivencia del pasado histórico acumulado en archivos bibliográficos y la vitalidad de la memoria personal, experimentada por el narrador / investigador como una forma de comunicación con el espacio que le rodea. Este momento nos obliga como lectores a habitar una porosa línea separatoria entre la historia y la memoria viva.

La narración en este momento es una manifestación de la memoria en el trasegar diario del novelista investigador que recibe una beca para escribir una obra. En varios momentos el investigador/narrador experimenta la activación imaginaria de la memoria de un pasado no experimentado, al ver a DeBry caminando, hablando, etc. El investigador/narrador explica a un profesor en Giesen que su investigación es difícil porque "pocos documentos se encuentran de Théodore de Bry en Fráncfort, y . . . su casa situada en la antigua Schüppengasse, así como los archivos históricos concernientes a los siglos XVI y XVII, fueron destruidos por las bombas aliadas" (Montoya 2015, 264), y entonces se ve obligado a justificar su presencia en la ciudad aludiendo a la importancia del contacto con el espacio como mecanismo y artefacto de memoria en sí mismo, al margen de lo escrito o archivado. "Algo habrá de aquel hombre que se inmiscuya en mi conciencia" al caminar por el casco viejo (Montoya 2015, 265). El lugar y las cosas del hombre del pasado funcionan como catalizadores de una imaginación histórica que conecta al librero protestante promotor de la leyenda negra de la conquista española, con un novelista descendiente de sujetos coloniales como aquellos a los que se refiere el texto de DeBry.

El momento de imaginación entonces aquí expresa el punto de contacto entre el presente y el pasado, ya no por medio del discurso histórico -aunque el investigador sigue un procedimiento de revisión de fuentes y archivos muy cercano al del historiador-, sino que sujeta dicho 
procedimiento histórico a las preguntas y precariedades del sujeto investigador. DeBry es un personaje preocupado y decepcionado por el carácter violento de la humanidad; y la empresa colonial en términos generales aparece completamente criticada por él. Pero el narrador quiere ir más allá de la formulación de esa mente imbuida en las circunstancias de su pasado y quiere imaginar "qué respondería Théodore De Bry si le refiero algunos eventos de mi época, no para angustiarlo, sino más bien para consolarlo ... Sí, le podría demostrar con suficiencia que, pese a las comodidades de la tecnología y las bondades de la ciencia, mi tiempo es quizás más pavoroso que el suyo" (Montoya 2015, 268-269). La particularidad de la historia de DeBry es una entre la multitud de violencias; y su representación parece de interés aquí sólo en tanto dé lugar al cuestionamiento del presente. La novela histórica de Montoya añade momentos en los que se enfatiza la incertidumbre y lo precario, como se observa cuando el narrador dice que quisiera detenerse y hablar con DeBry y contrastar su negatividad con los argumentos de los optimistas, pero "Théodore de Bry y yo no podemos hablar y nunca jamás lo haremos. Solo me resta verlo cómo se difumina definitivamente por los flancos de la iglesia" (Montoya 2015, 269). Desarma esta forma de conectar con el pasado, reconociéndole un carácter transitorio y que no puede superar la vulnerabilidad intrínseca que nos separa a todos del pasado de otros.

El capítulo dedicado al Exterminio en esta tercera narrativa vuelve a concentrarse en la descripción del registro visual del pasado, y aquí el narrador interviene específicamente para referirse a cómo percibe uno de los grabados de la edición de DeBry de Brevisima relación de la destrucción de las Indias de Bartolomé de las Casas, en el cual se ve a un español participando en el exterminio, como si bailara. Afirma entonces el autor implícito: "Cómo quisiera tener un aparato del futuro, semejante al que usa el Blade Runner de Ridley Scott, para buscar pistas identitarias en las fotografías. Un aparato que permita ir hasta el fondo de los rasgos de este baladrón ibérico" (Montoya 2015, 288). El registro visual sugiere un deseo de memoria activa en el cual se entendería todo el trasfondo identitario y particularizado del perpetrador del acto violento; pero dicho deseo es imposible de satisfacer, es más propio de una narrativa de ciencia ficción. En su lugar, nuestro narrador se conforma con los pequeños rasgos convencionalizados del dibujo y la acción que se ejecuta. Estos son los rastros precarios de esa identidad y, por tanto, como productor de símbolos que intervienen en la memoria de las violencias de la conquista, el narrador/novelista/investigador se muestra a sí mismo como precario y dominado por deseos de algún tipo de justicia inalcanzable.

\section{Conclusión}

Las tres narrativas de Pablo Montoya aquí estudiadas unen el presente con el pasado por medio de la écfrasis de archivos visuales. Estos archivos de alguna forma se deslizan hacia una memoria latente y oculta bajo capas de perspectivas históricas hegemónicas. La novelística de Montoya intenta la reactivación de dichas latencias al conectarse con las potencialidades afectivas de los cuerpos involucrados en la producción, acumulación y distribución de los artefactos visuales descritos. Se trata de una obra que no plantea la dominación de un material superado y que se entiende plenamente en sus complejas relaciones de causa y efecto; sino que antes bien se acerca a los aspectos imposibles de solucionar. La voz narrativa de Montoya vuelve los ojos sobre cómo los procesos de simbolización funcionan para darle al imperativo de justicia en el presente una dimensión humana que trasciende la generación presente y las fronteras nacionales. El mecanismo específico que sigue Montoya y que evoluciona a lo largo de su obra, es el de mover, entre el trasfondo de la atención y el primer plano de la misma, aquello que es parte del registro colectivo del pasado y las imágenes, símbolos y discursos que le dan peso cultural a dicho registro; y siempre sujetándolo a nociones de insuficiencia, precariedad y vulnerabilidad. Montoya no estabiliza la memoria como un discurso indudable y legitimador que estabiliza la violencia del pasado bajo un solo discurso, sino que la presenta como una dinámica de afectos vinculados a imágenes que, aunque altamente convencionalizadas (como la fotografía, la pintura, o la ilustración), están también profundamente vinculadas a un sufrimiento y una herida ausente que no por ellos menos se siente.

\section{Obras citadas}

Assmann, Astrid, and Linda Shortt. 2012. Memory and Political Change. New York: Palgrave MacMillan.

Erll, Astrid. 2011. Memory and Culture. Sarah B. Young, trad. New York: Palgrave Macmillan.

Fanta, Andrea, Alejandro Herrero-Olaizola, and Chloe Rutter-Jensen. 2017. "Territories of Conflict Through Colombian Cultural Studies”. Territories of Conflict. Rochester: University of Rochester Press: 1-20.

Gregg, Melisa, and Gregory J. Seigworth. 2010. "An Inventory of Shimmers". The Affect Theory Reader. Durham: Duke University Press: $1-25$.

LaRosa, Michael J, and Germán R. Mejía. 2017. Colombia. A Concise Contemporary History. London: Rowman \& Littlefield.

Montoya, Pablo. 2008. Lejos de Roma. Medellín: Sílaba. 
2009. Novela histórica en Colombia 1988-2008. Entre la pompa y el fracaso. Medellín: Editorial Universidad de Antioquia.

2012. Los derrotados. Medellín: Sílaba.

2015. Tríptico de la infamia. Bogotá: Penguin Random House.

Restrepo, Juan Felipe. 2005. "Erotismo y fotografía en La sed del ojo de Pablo Montoya". Estudios de literatura colombiana No. 16 (enero-junio): 209-217.

Sontag, Susan. 2003. Regarding the Pain of Others. New York: Picador.

Vallejo, Norberto. 2017. "Bolívar contado por los escritores colombianos". El club de lectura. Podcast audio, oct. 12 de 2017. http://alacarta.caracol.com.co/audio/097RD010000000587206/. 